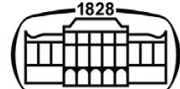

AKADÉMIAI KIADÓ

European Journal of

Microbiology and

Immunology

$10(2020) 3,115-124$

DOI:

$10.1556 / 1886.2020 .00022$

(c) 2020 The Authors

\section{REVIEW PAPER}

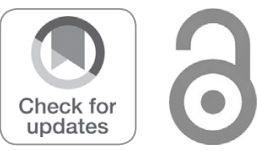

\title{
Review of therapeutic options for infections with carbapenem-resistant Klebsiella pneumoniae
}

\author{
RASMUS G. BANDICK, SORAYA MOUSAVI, \\ STEFAN BERESWILL and MARKUS M. HEIMESAAT*
}

Institute of Microbiology, Infectious Diseases and Immunology, Gastrointestinal Microbiology Research Group, Charité - University Medicine Berlin, Corporate Member of Freie Universität Berlin, Humboldt-Universität zu Berlin, Berlin Institute of Health, Berlin, Germany

Received: July 28, $2020 \bullet$ Accepted: August 25, 2020

Published online: September 17, 2020

\begin{abstract}
Infections with multi-drug resistant (MDR) bacteria including carbapenem-resistant Klebsiella pneumoniae are emerging worldwide but are difficult to treat with the currently available antibiotic compounds and therefore constitute serious threats to human health. This prompted us to perform a literature survey applying the MEDLINE database and Cochrane Register of Controlled Trials including clinical trials comparing different treatment regimens for infections caused by carbapenem-resistant $K$. pneumoniae. Our survey revealed that a combined application of antibiotic compounds such as meropenem plus vaborbactam, meropenem plus colistin and carbapenem plus carbapenem, resulted in significantly increased clinical cure and decreased mortality rates as compared to respective control treatment. However, further research on novel antibiotic compounds, but also on antibiotic-independent molecules providing synergistic or at least resistance-modifying properties needs to be undertaken in vitro as well as in large clinical trials to provide future options in the combat of emerging lifethreatening infections caused by MDR bacteria.
\end{abstract}

\section{KEYWORDS}

antimicrobial resistance, multi-drug resistant enterobacteria, carbapenem-resistant Klebsiella pneumoniae, KPC producing bacteria, novel antimicrobial therapies, nosocomial infections, randomized clinical trials, intervention studies

\section{INTRODUCTION}

\section{Current situation}

Emerging antimicrobial resistance of bacterial strains constitutes a worldwide major threat to mankind [1]. Lately, the race between the development of novel antibiotics and the progressive emergence of multi-drug resistant (MDR) bacterial strains has been highlighted, emphasising and contextualizing the role of "one health" [2]. This might be even further aggravated by the current wide use of antibiotics for the treatment of COVID-19 patients, in an attempt to prevent and treat bacterial superinfections. This is why early on US-American physicians highlighted the importance of thoughtful antibiotic stewardship in general and in treating COVID-19 patients in particular $[3,4]$.

Corresponding author. Department 0 Microbiology, Infectious Diseases and Immunology, Charité - University Medicine Berlin, CC5, Campus Benjamin Franklin, FEM, Garystr. 5, D14195, Berlin, Germany. Tel.: +4930450524318 E-mail: markus.heimesaat@charite.de

\section{Antimicrobial resistance}

Acquired resistance of pathogens to antimicrobial therapeutics is not a novel phenomenon and has been observed since the implementation of antibiotics [5, 6]. Resistance primarily arises from the natural disposition or structure of pathogens and antimicrobial molecules [7]. Additionally, resistance develops through selection pressure by applied antimicrobial therapeutic compounds [8]. Known mechanisms of bacterial resistance include alterations to the targeted binding sites, production of enzymes which inactivate the drug, and reduced 
expression of influx mechanisms or reinforcement of efflux pumps $[9,10]$. The group of $\beta$-lactam antibiotics constitutes one of the most utilized antimicrobial class for treating patients with bacterial infections [11]. These types of antibiotics are characterised by a common $\beta$-lactam-ring and can be divided into penicillins, monobactams, cephamycins, cephalosporins, $\beta$-lactamase inhibitors and carbapenems, which hinder bacterial growth by inhibiting transpeptidases of the cell wall synthesis upon binding to penicillin-binding proteins. Bactericidal effects are achieved through subsequent lysis of the bacteria, after activating autolytic enzymes that are already present in the bacterial cell wall $[6,12]$. Carbapenem antibiotics have been used for approximately 40 years until now, exhibit a wider antimicrobial spectrum as compared to penicillins or cephalosporines, for instance, and are usually reserved for the treatment of severe infections, particularly caused by MDR bacteria, given that carbapenems are effective even when extended-spectrum $\beta$ lactamases (ESBL) are expressed by the pathogen $[12,13]$.

During the last decades, an alarming rise in infections caused by carbapenem-resistant bacteria has been observed all around the world posing a global threat to human health $[2,14]$. In 2018, for instance, in some European countries such as Greece, Romania and Italy 63.9, 29.5 and $26.8 \%$ of clinical enterobacterial isolates have been tested resistant against carbapenems, respectively [14]. Notably, in low- and middle-income countries the prevalence rates in carbapenem resistance have been even more progressively rising [15, 16] posing a more pronounced threat to infected patients given that individuals are more prone to severe infection due their poorer living conditions, fewer treatment options and higher abundances of immunosuppressive co-morbidities $[17,18]$.

\section{Carbapenem-resistant Klebsiella pneumoniae}

The gastrointestinal tract is inhabited by a multitude of microorganisms forming the complex commensal gut microbiota $[6,10]$. Under certain circumstances, however, human bacterial infections might arise from commensal gut bacteria such as Gram-negative enterobacteria including Escherichia coli and Klebsiella species (spp.), further by Enterobacter, Pseudomonas and Bacteroides spp., or by Gram-positive enterococci, for instance $[6,10]$. In general, all of these bacterial species are prone to antimicrobial resistance development. In particular, MDR Klebsiella pneumoniae and Pseudomonas aeruginosa as well as vancomycin-resistant enterococci (VRE) are frequently observed etiologic agents of nosocomial (i.e., hospital-acquired) infections [19].

The Klebsiella genus is part of the Enterobacteriaceae family, nowadays divided into $K$. pneumoniae subspecies (ssp.) pneumoniae (here termed K. pneumoniae), K. pneumoniae ssp. ozaenae, $K$. pneumoniae ssp. rhinoscleromatis and Klebsiella oxytoca $[10,20]$. K. pneumoniae are Gramnegative, immotile, aerobic bacilli that are able to express a polysaccharide capsule, classified by K-serotypes, enabling biofilm formation. K. pneumoniae might cause genito- urinary tract infections, bloodstream and catheter-associated infections, intraabdominal infections such as abscesses and furthermore, respiratory tract infections such as pneumonia, lung abscesses and empyema $[6,21]$. Antimicrobial resistance of $K$. pneumoniae might be directed against $\beta$-lactam antibiotics such as cephalosporins upon ESBL production, against carbapenems upon production of $K$. pneumoniae carbapenemases (KPC) or New Delhi metallo- $\beta$-lactamase (NDM) and even against polymyxins through Mobilized Colistin Resistance upon production of phosphatidylethanolamine transferases [22]. Infections with these MDR strains are often (if at all) difficult to treat, especially in neonatal, elderly and otherwise immunocompromised patients $[23,24]$.

Therefore, we here aimed at providing a comprehensive review of treatment options for patients infected with carbapenem-resistant K. pneumoniae.

\section{MATERIAL AND METHODS}

The here presented a systematic review of the literature was performed according to the recommendations within the advisory handbook of the Cochrane Foundation [25] and according to the regulations on good scientific practice of the Charité - Universitätsmedizin Berlin [26].

\section{Search strategy}

For identifying relevant studies, a search in the MEDLINE database was performed using the NIH-search engine PubMed. The period for designed search query was from June 8 to 26, 2020. A later search in the Cochrane Central Register of Controlled Trials from July 6 to 13, 2020 resulted in additional eligible studies. The terms used in the literature search were composed of free text seeking to encompass all relevant studies. The query applied in PubMed combined terms for infections with $K$. pneumoniae and for carbapenem-resistant strains and respective synonyms with the Boolean operator AND. The search in MEDLINE was as follows:

\section{((K. pneumoniae) OR (Klebsiella infection)) AND}

((carbapenem-resistant enterobacteriaceae) OR (carbapenem resistance) $O R$ (K. pneumoniae carbapenemase)),

resulting in 2624 hits published between 1983 and 2020. These were filtered for "clinical trials" based on their registration in the database which yielded 45 results. In the Cochrane central register of controlled trials 64 trials were found.

\section{Inclusion and exclusion criteria}

We included studies that focused on patients infected with carbapenem-resistant $K$. pneumoniae isolates that were subjected to different antimicrobial treatment regimens. Respective control groups should consist of comparable individuals receiving different treatments, which were analysed for superiority or inferiority using clinical endpoints 
such as mortality and/or cure. These clinical studies should have been designed as randomized controlled trials (RCTs). Studies primarily assessing minimal inhibitory concentrations (MICs) or biochemical and pharmacological mechanisms were excluded. If studies were not restricted to $K$. pneumoniae, but mainly referred to enterobacteria or Gramnegative bacteria as infectious agents, respective investigations pertaining to this review were mentioned as supplementary information. Furthermore, only studies written in English or German were included. There was no restriction on publication dates until July 2020, however, only published studies were included. Screening for relevant publications was performed by assessing the titles and abstracts of the papers. If no conclusive decision could be drawn, the full text was read.

\section{Data extraction}

The design and results of the selected studies were documented in sheets containing information such as categories of study design, composition of trial populations, study drugs and comparators, targeted infections and causative strains and main results.

\section{RESULTS}

\section{Characteristics of included studies}

Upon application of the defined criteria 95 studies were screened for this review, of which 83 were excluded due to lack of adherence to the inclusion criteria (e.g., no clinical trial, not referring to K. pneumoniae infections, no comparisons of different treatment regimens). After exclusion of one review article and one poster abstract, the remaining ten articles were checked for eligibility and removed if not freely accessible. Five studies published between 2015 and 2018 were eligible for a qualitative assessment of which four were RCTs [27-30] and one was a retrospective, observational study [31] (Tables 1 and 2). Additional six publications that were not entirely fulfilling the inclusion criteria were at least included in the screening, but not eligible for comparisons (i.e., no comparative treatment regimens, missing control cohorts, too small sample sizes, not explicitly referring to $K$. pneumoniae infections) [32-37]. Given their valuable contribution to the field, however, the main aspects of the studies were summarized as supplementary information at the end of this review (Table 3).

The main methodological approaches applied in the five main studies included in this review are summarized in Table 1. The included studies exhibited a comparable experimental setup and except for the study by De Pascale et al. [31] employed the structure of an RCT. Three studies focussed on patients in intensive care units (ICUs) [29-31]. In all studies, only patients suffering from infections (such as pneumonia, urinary tract infections or intraabdominal infections) caused by carbapenem-resistant pathogens were included. The distinct resistance mechanisms were assessed by either determining specific resistance genes or the MIC of respective bacterial strains. The study by Paul et al. included mostly patients infected with other Gram-negative bacteria such as $P$. aeruginosa or Acinetobacter baumannii, whereas the Enterobacteriaceae including Klebsiella spp., however, were summarized within a subgroup [30]. Overall, the sizes of the study populations were comparable: whereas in the intervention groups 35 participants were included, the control groups consisted of 40 individuals on average (Table 1). Likewise, the age distribution was similar in respective studies, ranging from 55.5 to 69.2 years of age. In three studies slightly more females were included, whereas in two studies this held true for male patients. Furthermore, the medical preconditions in the subjects included in the intervention and control groups were comparable (Table 1).

\section{Results from included studies}

Table 2 summarizes the most relevant results of the included studies. Ji et al. designed a trial to test the antimicrobial effects of a combination of cefepime plus amoxicillin with clavulanic acid versus tigecycline in the treatment of patients infected with hospital-acquired KPC producing K. pneumoniae [27]. The isolated pathogens showed high-grade resistance to carbapenems and cephalosporins. However, upon combining cefepime with amoxicillin-clavulanic acid, significant synergistic effects in reducing the MIC against respective antimicrobial substances could be obtained in vitro. When compared with the tigecycline groups, the mortality and the pathogen clearance rates were similar in the cefepime plus amoxicillin-clavulanic acid cohort $(P=0.311$ and 0.447 , respectively), whereas the clinical outcome was slightly better in the latter [27]. Due to the diverse spectrum of combinations applied in the tigecycline groups resulting in small sample sizes, however, reliable subgroup analyses were restricted. The authors also addressed the economic aspects of respective treatment regimens given financial restraints in their clinical setting and estimated that the overall expenses upon the antibiotic combination of cefepime with amoxicillin-clavulanic acid to be lower as compared to the applied tigecycline treatment regimens [27].

Wunderink et al. analysed the results of the TANGO II trial on treating infections with KPC-producing Enterobacteriaceae with meropenem plus vaborbactam [28], a therapy combining a carbapenem and a novel boronic-acid $\beta$-lactamase-inhibitor [38, 39]. Notably, the best available therapy (BAT) was considered as control group, but had to discontinue after preliminary evaluation by the monitoring board, claiming significant disadvantages for the control patients [28]. Treatment with meropenem plus vaborbactam resulted in a significant higher rate of both, clinical and test of cure at the end of treatment $(P=0.03$ and 0.02 , respectively) [28]. Although not statistically significant, a trend towards lower mortality rates could be observed as well, which was accompanied by slightly lower rates of adverse treatment events in the intervention group, especially when assessing renal side effects [28].

Abdelsalam et al. and Paul et al. designed studies to test the potential superiority of a meropenem plus colistin 
Table 1. Methodological characteristics of included studies and composition of the study populations

\begin{tabular}{|c|c|c|c|c|c|c|c|}
\hline \multirow[b]{2}{*}{ Study } & \multirow[b]{2}{*}{ Design } & \multirow[b]{2}{*}{ Setting } & \multirow[b]{2}{*}{ Strains } & \multicolumn{2}{|c|}{ Study population $(n)$} & \multicolumn{2}{|c|}{ Demographics (mean) } \\
\hline & & & & Intervention & Control & Intervention & Control \\
\hline Ji et al. 2015 [27] & RCT, blinded & Nosocomial infections & All $b l a_{\mathrm{KPC}}$-positive & 26 & 25 & $\begin{array}{c}67.1 \text { years } \\
69.2 \% \text { male }\end{array}$ & $\begin{array}{l}63.6 \text { years } \\
52 \% \text { male }\end{array}$ \\
\hline $\begin{array}{l}\text { Wunderink et al., } 2018 \\
\text { [28] }\end{array}$ & RCT, blinded & HAP/VAP, bacteraemia, cIAI & $\begin{array}{l}\text { Fortyseven patients with CRE: } 29 \\
\text { cases with K. pneumoniae } \\
\text { infection in intervention and } 12 \text { in } \\
\text { control }\end{array}$ & 32 & 15 & $\begin{array}{l}63.5 \text { years } \\
56 \% \text { female }^{\mathrm{a}}\end{array}$ & $\begin{array}{l}60.2 \text { years } \\
33.3 \% \\
\text { female }\end{array}$ \\
\hline $\begin{array}{l}\text { Abdelsalam et al., } 2018 \\
\text { [29] }\end{array}$ & RCT, blinded & ICU, HAP/VAP & $\begin{array}{l}\text { Sixty patients with } K \text {. pneumoniae } \\
\text { infection, in intervention and } \\
\text { control group } 26 \text { and } 23 \text { labelled } \\
\text { MDR (carbapenem-resistant) }\end{array}$ & 30 & 30 & $\begin{array}{l}55.9 \text { years } \\
60 \% \text { female }\end{array}$ & $\begin{array}{l}56.2 \text { years } \\
47 \% \text { female }\end{array}$ \\
\hline Paul et al., 2018 [30] & RCT, blinded & ICU & $\begin{array}{l}\text { Seventythree infections with } \\
\text { Enterobacteriaceae, } 66 \text { of these } \\
\text { with K. pneumoniae, other } 312 \mathrm{~A} \text {. } \\
\text { baumannii and } 21 \mathrm{P} \text {. aeruginosa }\end{array}$ & $39 / 208$ & $34 / 198$ & $\begin{array}{l}66 \text { years } \\
63 \% \text { female }^{\mathrm{b}}\end{array}$ & $\begin{array}{l}66 \text { years } \\
62 \% \text { female }\end{array}$ \\
\hline $\begin{array}{l}\text { De Pascale et al., } 2017 \\
\text { [31] }\end{array}$ & $\begin{array}{l}\text { Retrospective observation study, } \\
\text { matched case-control }\end{array}$ & $\begin{array}{c}\text { ICU, no restriction on infection } \\
\text { type }\end{array}$ & $\begin{array}{c}90 \% \text { bla } a_{\mathrm{KPC}} \text {-positive } \\
\text { 10\% class } \mathrm{B} / \mathrm{D} \beta \text {-lactamases } \\
66 \% \text { XDR-strains in intervention } \\
32.3 \% \text { XDR-strains in control } \\
\text { group }\end{array}$ & 48 & 96 & $\begin{array}{l}55.5 \text { years } \\
72 \% \text { male }\end{array}$ & $\begin{array}{l}61.3 \text { years } \\
60.4 \% \text { male }\end{array}$ \\
\hline
\end{tabular}

RCT, randomized controlled trial; HAP/VAP, hospital/ventilator acquired pneumonia; cIAI, complicated intraabdominal infection; CRE, carbapenem-resistant Enterobacteriaceae; ICU, intensive care unit; MDR, multi-drug resistant; XRD, extensively-drug resistant.

${ }^{a}$ Wunderink et al. The demographic data noted here is related to the whole study group. Authors did not provide detailed information on the K. pneumoniae subgroup.

${ }^{\mathrm{b}} \mathrm{Paul}$ et al. The demographic data noted here is related to the whole study population; no detailed information on the Enterobacteriaceae subgroup given. 
Table 2. Results of included studies

\begin{tabular}{|c|c|c|c|c|c|c|c|c|}
\hline \multirow[b]{2}{*}{ Study } & \multicolumn{2}{|c|}{ Applied agents of study group } & \multicolumn{2}{|c|}{ Dosage and duration } & \multicolumn{4}{|c|}{ Outcome } \\
\hline & Intervention & Comparator & Intervention & Comparator & Endpoint $^{\mathrm{a}}$ & Intervention & Comparator & $\begin{array}{c}P- \\
\text { Value }\end{array}$ \\
\hline \multirow[t]{2}{*}{ Ji et al., 2015 [27] } & $\begin{array}{l}\text { Cefepime }+ \text { amoxicillin- } \\
\text { clavulanic } \text { acid }^{\mathrm{b}}\end{array}$ & $\begin{array}{l}\text { Tigecycline monotherapy } \\
\text { or combined }^{c}\end{array}$ & $1 \mathrm{~g}+1.2 \mathrm{~g} \mathrm{q} 6 \mathrm{~h}$ for $10 \mathrm{~d}$ & $\begin{array}{l}\text { loading dose, } 100 \mathrm{mg} \text {, } \\
\text { decreased to } 50 \mathrm{mg} \mathrm{q} 12 \mathrm{~h}\end{array}$ & $\begin{array}{l}\text { mortality } \\
\quad \mathrm{d} 28\end{array}$ & $23.1 \%$ & $36 \%$ & 0.311 \\
\hline & & & & for $10 \mathrm{~d}$ & eradication & $57.7 \%$ & $68 \%$ & 0.447 \\
\hline \multirow{3}{*}{$\begin{array}{l}\text { Wunderink et al., } \\
2018 \text { [28] }\end{array}$} & Meropenem-vaborbactam & $\mathrm{BAT}^{\mathrm{d}}$ & $2 \mathrm{~g}$ and $2 \mathrm{~g} \mathrm{q} 8 \mathrm{~h}$ for $7-14$ & according to chosen BAT & clinical cure & $59.4 \%$ & $26.7 \%$ & 0.03 \\
\hline & & & $\mathrm{d}$ & by respective investigator & $\begin{array}{l}\text { mortality } \\
\text { d28 }\end{array}$ & $15.6 \%$ & $33.3 \%$ & 0.19 \\
\hline & & & & & eradication & $53.1 \%$ & $33.3 \%$ & 0.20 \\
\hline \multirow{2}{*}{$\begin{array}{l}\text { Abdelsalam et al., } \\
2018 \text { [29] }\end{array}$} & Meropenem-colistin & Colistin monotherapy & Meropenem: $1 \mathrm{~g} \mathrm{q} 8 \mathrm{~h}$ & Colistin: $300 \mathrm{mg}$ loading & clinical cure & $83.3 \%$ & $56.7 \%$ & 0.047 \\
\hline & & & & $\begin{array}{c}\text { and } 100 \mathrm{mg} \text { maintenance } \\
\text { dose } \mathrm{q} 8 \mathrm{~h}\end{array}$ & mortality & $16.7 \%$ & $43.3 \%$ & 0.047 \\
\hline \multirow[t]{3}{*}{$\begin{array}{l}\text { Paul et al., } 2018 \\
\text { [30] }\end{array}$} & Meropenem-colistin & Colistin monotherapy & Meropenem: $2 \mathrm{~g} \mathrm{q} 8 \mathrm{~h}$ & $\begin{array}{l}\text { Colistin: 9MIU loading } \\
\text { and 4.5MIU maintenance }\end{array}$ & $\begin{array}{l}\text { clinical } \\
\text { failure }\end{array}$ & $46 \%$ & $68 \%$ & 0.185 \\
\hline & & & & dose $\mathrm{q} 12 \mathrm{~h}$ & $\begin{array}{l}\text { mortality } \\
\text { d228 }\end{array}$ & $21 \%$ & $35 \%$ & 0.235 \\
\hline & & & & & $\begin{array}{l}\text { eradication } \\
\text { failure }^{\mathrm{e}}\end{array}$ & $15 \%$ & $18 \%$ & 0.838 \\
\hline \multirow{4}{*}{$\begin{array}{l}\text { De Pascale et al., } \\
2017 \text { [31] }\end{array}$} & Double carbapenem & Therapy with gentamicin, & Ertapenem and & Colistin: 9MIU/d q12 h, & clinical cure & $62.5 \%$ & $48.9 \%$ & 0.17 \\
\hline & $(\text { always ertapenem })^{f}$ & tigecycline, or colistin ${ }^{\mathrm{g}}$ & $\begin{array}{c}\text { meropenem: } 2 \mathrm{~g} \text { and } 6 \mathrm{~g} \\
12 / 24 \mathrm{~h} \text { and } \mathrm{q} 8 \mathrm{~h}\end{array}$ & $\begin{array}{l}\text { Gentamicin: } 5 / 7 \mathrm{mg} / \mathrm{kg} \\
\text { q24 h, Tigecycline: } 200\end{array}$ & $\begin{array}{l}\text { mortality } \\
\mathrm{d} 28\end{array}$ & $29.2 \%$ & $47.9 \%$ & 0.04 \\
\hline & & & & $\begin{array}{l}\text { mg loading dose and } 100 \\
\mathrm{mg} \mathrm{q} 12 \mathrm{~h}\end{array}$ & $\begin{array}{l}\text { mortality } \\
\text { d90 }\end{array}$ & $50 \%$ & $60.4 \%$ & 0.31 \\
\hline & & & & & eradication & $50 \%$ & $38.3 \%$ & 0.27 \\
\hline
\end{tabular}

${ }^{\mathrm{a}}$ For eradication parameters like microbiological cure or pathogen clearance were included.

bi et al. Two received additional fosfomycin.

${ }^{c} \mathrm{Ji}$ et al. Combination therapy with fosfomycin, amikacin-levofloxacin, cefepime, cefoperazone-sulbactam, or meropenem, $52 \%$ of therapeutic schemes were combination therapies, otherwise tigecycline monotherapy.

${ }^{\mathrm{d}}$ Wunderink et al. Best available therapy (BAT) meaning monotherapy or combination of polymyxin, carbapenem, aminoglycoside, tigecycline, or ceftazidime-avibactam.

e Paul et al. The outcome reported belongs to a subgroup of patients with Enterobacteriaceae infections, for the whole study group reported outcome percentages were consistently higher.

${ }_{\mathrm{f}}^{\mathrm{f}}$ e Pascale et al. Combination added to double carbapenem therapy in intervention group for 35/48 patients: colistin (19), gentamicin (8), tigecycline (3), colistin and gentamicin (3), and colistin and tigecycline (2).

${ }^{\mathrm{g}}$ De Pascale et al. Combination therapies in control group in 52/96 cases, consisting of colistin and tigecycline (22), colistin and gentamicin (13), gentamicin and tigecycline (7), colistin,

tigecycline and gentamicin (7). 
Table 3. Overview of studies from screening that were not eligible for inclusion

\begin{tabular}{|c|c|c|c|c|}
\hline Study & $\begin{array}{l}\text { Intervention vs. } \\
\text { Comparator }\end{array}$ & Study population & Outcome comparison & Reason for exclusion \\
\hline $\begin{array}{l}\text { Kaye et al., } \\
2018 \text { [32] }\end{array}$ & $\begin{array}{l}\text { Meropenem-vaborbactam } \\
\text { vs. piperacillin-tazobactam }\end{array}$ & $\begin{array}{c}30 K p / 274(1 \mathrm{CR}-K p) \text { vs. } 28 \\
K p / 276(2 \mathrm{CR}-K p)\end{array}$ & $\begin{array}{l}98.4 \% \text { vs. } 94 \% \text { clinical cure, } \\
66.3 \% \text { vs. } 60.4 \% \text { eradication }\end{array}$ & $\begin{array}{l}\text { Main pathogen } E \text {. coli. Too } \\
\text { few } K p \text { non-susceptible to } \\
\text { meropenem. Design not } \\
\text { fitted to evaluate effect on } \\
\text { CR pathogens }\end{array}$ \\
\hline $\begin{array}{l}\text { Lucasti et al., } \\
2016[33]\end{array}$ & $\begin{array}{l}\text { Relebactam + imipenem- } \\
\text { cilastatin vs. placebo }+ \\
\text { imipenem-cilastatin }\end{array}$ & $\begin{array}{c}22 K p / 167 \text { (none CR) vs. } 12 \\
K p / 83 \text { (none CR) }\end{array}$ & $\begin{array}{l}22 / 22 \text { vs. } 10 / 12 \text { clinical } \\
\text { response }\end{array}$ & $\begin{array}{c}\text { Focus on other pathogens, } \\
\text { small number of resistant } \\
\text { overall, no CR-Kp. Many } \\
\text { polymicrobial }\end{array}$ \\
\hline $\begin{array}{l}\text { Mendes et al., } \\
2018 \text { [34] }\end{array}$ & $\begin{array}{l}\text { Ceftazidime-avibactam vs. } \\
\text { doripenem }\end{array}$ & $\begin{array}{c}2 \text { CR-Kp (OXA-48)/393 vs. } \\
2 \text { CR-Kp (OXA- } 48, \text { NMD- } \\
1) / 417\end{array}$ & $\begin{array}{l}\text { Clinical cure observed in } 2 \\
\text { vs. clinical cure in NDM-1 } \\
\text { and intermediate in OXA- } \\
48\end{array}$ & $\begin{array}{l}\text { Main resistance mediated } \\
\text { by bla }{ }_{\text {CTX-M }} \text {, too few CR-Kp }\end{array}$ \\
\hline $\begin{array}{l}\text { Mendes et al., } \\
2019 \text { [35] }\end{array}$ & $\begin{array}{c}\text { Ceftazidime-avibactam vs. } \\
\text { BAT }\end{array}$ & 8 CRE/149 vs. 6 CRE/146 & $\begin{array}{c}100 \% \text { clinical cure and } 50 \% \\
\text { eradication vs. } 66.7 \% \text { and } \\
50 \%\end{array}$ & $\begin{array}{l}\text { Only } 11 \mathrm{Kp} \text { of } 14 \mathrm{CRE} \text {. } \\
\text { Mainly ceftazidime- } \\
\text { resistance (bla } \mathrm{CTX-M} \\
\text { conveyed) }\end{array}$ \\
\hline $\begin{array}{l}\text { Michalopoulos } \\
\text { et al., } 2010 \\
\text { [36] }\end{array}$ & $\begin{array}{l}\text { Fosfomycin (combination } \\
\text { with colistin [6], gentamicin } \\
\text { [3], or piperacillin- } \\
\text { tazobactam [1]) }\end{array}$ & $11 \mathrm{CR}-K p$ & $\begin{array}{l}\text { Good clinical and } \\
\text { microbiological outcome } \\
\text { reported, } 18.2 \% \text { mortality } \\
\text { vs. } 6.9 \% \text { mortality in ICU }\end{array}$ & $\begin{array}{c}\text { No comparison group, } \\
\text { small sample size, and } \\
\text { subgroups of combination } \\
\text { therapy. }\end{array}$ \\
\hline $\begin{array}{l}\text { Motsch et al., } \\
2019 \text { [37] }\end{array}$ & $\begin{array}{l}\text { Relebactam }+ \text { imipenem vs. } \\
\text { colistin }+ \text { impenem }\end{array}$ & $3 K p / 31$ vs. $1 K p / 16$ & $\begin{array}{c}\text { Overall favourable outcome } \\
33.3 \% \text { vs. } 100 \%\end{array}$ & $\begin{array}{l}\text { Main pathogen } P \text {. } \\
\text { aeruginosa, too small } \\
\text { sample for statistical } \\
\text { evaluation }\end{array}$ \\
\hline
\end{tabular}

Kp, Klebsiella pneumoniae; CR-Kp, carbapenem-resistant K. pneumoniae; CR, carbapenem-resistant; OXA-48, oxacillinase mediated resistance, $\beta$-lactam-carbapenemase firstly described in 2004 ; NMD-1, New Delhi metallo- $\beta$-lactamase, carbapenemase firstly described in 2008; bla CTX-M , family of $\beta$-lactamase coding genes for cefotaxime-resistance; ICU, intensive care unit.

combination therapy as compared to colistin monotherapy in patients infected with carbapenem-resistant bacterial strains [29, 30]. Therefore, Abdelsalam et al. enrolled 30 patients infected with carbapenem-resistant K. pneumoniae in the intervention and control groups, whereas Paul et al. included more patients infected with Gram-negative bacteria and discussed the analysis of the subgroup outcomes for Enterobacteriaceae, most of which were K. pneumoniae. Abdelsalam et al. reported significantly higher clinical cure and reduced mortality rates upon meropenem plus colistin versus the colistin treatment alone and hence, the superiority of the former as compared to the latter regimen [29]. In contrast, Paul et al. showed that in case of A. baumannii infections the combinatory intervention strategy was not superior when compared to the monotherapy given comparable outcomes in intervention and control groups [30]. However, when focussing on carbapenem-resistant Enterobacteriaceae including K. pneumoniae at least a trend towards lower clinical failure and mortality rates were observed (not statistically significant) [30].

De Pascale et al. followed a different, rather unconventional approach, by testing the application of a double-carbapenem therapy for the treatment of carbapenem-resistant $K$. pneumoniae, as compared to the standard monotherapy [31]. The rationale behind this approach was that in cases of severe infections and existing contraindications for gentamicin or colistin based treatments, the application of ertapenem might comparatively inhibit produced carbapenemases, resulting in an enhanced activity of the added second carbapenem. Remarkably, the authors were able to show a significant reduction in mortality on day 28, pointing towards a survival benefit following the carbapenem-carbapenem combination as compared to the carbapenem monotherapy [31]. In case of mortality rates later during the course of infection (i.e., on day 90), however, the differences between intervention and control groups became less distinct. Furthermore, when assessing clinical cure and clearance of the pathogen the differences were not statistically significant, although a trend towards higher respective rates could be assessed [31].

In summary, all included studies reported a higher rate of clinical cure associated outcomes and reduced mortality in the intervention groups under investigation when compared to the respective control cohorts as summarized in Table 2.

\section{Supplementary information from non-eligible studies}

The studies that were not included into the main review, but provided valuable supplementary information had tested a broad spectrum of antibiotic compounds against infections with KPC producing clinical bacteria isolates as summarized in Table 3. 
Kaye et al. designed the randomized clinical control TANGO I trial [32], assessing the effects of meropenem plus vaborbactam versus piperacillin plus tazobactam in the cure of complicated urinary tract infections that were mainly due to pathogenic E. coli. However, numbers of patients infected with KPC producing K. pneumoniae were too small to draw any conclusions. In the RECAPTURE and REPRISE trials Mendes et al. surveyed the effects of ceftazidime plus avibactam versus doripenem in MDR enterobacteria, but the numbers of cases due to carbapenem-resistant K. pneumoniae infections were very limited $[34,35]$. This also held true for studies performed by Lucasti et al. and Motsch et al. who applied the novel bicyclic diazabicyclooctane based $\beta$-lactamase-inhibitor relebactam [33, 37], that is proposed for combination with imipenem against KPC producing isolates among others [39]. In a study by Michalopoulos et al. ICU patients suffering from carbapenem-resistant K. pneumoniae infections were treated with fosfomycin (without or with colistin or gentamicin) versus piperacillin plus tazobactam. The authors concluded that based upon the obtained results the former therapeutic approach might be considered for the treatment of critically ill patients in general, but the limited numbers of included patients $(n=11)$ did not warrant any further conclusions [36].

\section{DISCUSSION}

\section{Main findings}

The literature survey presented here revealed a multitude of approaches to treat patients suffering from infections caused by MDR, including carbapenemase-producing K. pneumoniae exceeding the spectrum of current guidelines and conventional therapies to date. The RCT designed as multicenter studies investigated substantial numbers of probands in endemic settings.

Collectively, the studies revealed superior treatment results within the interventive cohorts as compared to respective control groups. For instance, in the TANGO II trial the combination of meropenem plus avibactam resulted in an enhanced clinical cure [28], whereas treatment with a meropenem-colistin combination improved both, clinical cure and mortality rates in critically ill patients suffering from pneumonia [29]. Furthermore, the application of double-carbapenems for the treatment of patients infected with carbapenem-resistant K. pneumoniae strains revealed a significant beneficial effect on short term mortality (i.e., day 28), clinical signs of infection and clearance of the pathogen hence, pointing towards a promising approach to tackle difficult-to-treat infections in problematic epidemiological settings [31].

Even though some studies did not provide statistically significant results the interventive strategies under investigation might give valuable hints towards promising future novel or adjunct therapeutic strategies. The use of novel $\beta$ lactamase inhibitors such as vaborbactam and relebactam in combination with carbapenem antibiotics, for instance, may reopen therapeutic windows that were previously closed. Different studies revealed an advantageous outcome upon a combined application of antibiotic compounds such as cefepime-amoxicillin/clavulanic acid [27] and meropenemcolistin [29, 30], for instance. These promising results are further supported by Tumbarello et al. who found that a combinatory antibiotic therapy of carbapenemase-producing $K$. pneumoniae bloodstream infections consisting of meropenem, colistin, gentamicin and/or tigecycline was superior $(P=0.02)$ when compared to monotherapy [40].

One needs to take into consideration, however, that in several studies the clinical evidence is limited by the relatively low numbers of included patients. It would be thus highly desirable to base these observations on larger pools of subjects, which is hindered by the critical state of most of the included patients and furthermore, the paucity of resources.

\section{Limitations}

Since this review does not stretch to the statistical evaluation of a meta-analysis, the evaluation of biases is only subjective. Firstly, the designs of the included studies promise high levels of evidential results, since they were based on ethical planning, were prospectively randomized and included comparable control groups, in which occurring drop-outs were mostly documented and explained. The baseline of the study populations was balanced, but the risk of undocumented confounders was very high, considering the relatively small sample sizes. Blinding in the studies, double or single, increased their quality. In addition, the applied therapeutic regimens differed, since the comparison of dosage and duration of therapy was not possible. Furthermore, comparative subgroups with combined drugs further resulted in restricted sample sizes which impacted the significance of results.

As this review of studies was performed by one investigator, all conclusions should be considered cautiously. Although the literature survey was undertaken with consideration of possible sources, the screening and interpretation pose risks of inherent bias given that there might still be data not published or relevant research not retrieved during this search.

\section{CONCLUSION AND PERSPECTIVES}

The here reviewed studies were not conclusive on definitive best possible treatment(s). As good antibiotic stewardship mandates, antimicrobial susceptibility testing is recommended for therapy planning, yet this analysis lays ground for possible therapeutic approaches, including carbapenems even in cases of assumed resistance of infectious agents, if used in combination or combined with $\beta$-lactamase inhibitors, for instance. Therefore, the studies showing significant effects such as clinical cure and decreased mortality upon treatment with meropenem-vaborbactam, meropenem-colistin and double-carbapenem in critically ill patients suffering from severe infections caused by 
carbapenemase-producing K. pneumoniae need to be highlighted in particular [28-31].

Very recent studies further provide promising perspectives in the combat of infections with MDR pathogens. For instance, the new aminoglycoside plazomicin showed broad antimicrobial effects against Gram-negative bacteria, including carbapenemase-producing strains [41]. This pharmacological review article described the effects of plazomicin in complicated urinary tract infections, mostly effective against carbapenem-resistant $K$. pneumoniae, including KPC-positive pathogens, based on clinical trials [42]. This study was further supported by a larger clinical trial indicating the favourable application of plazomicin for the treatment of complicated urinary tract infections due to Enterobacteriaceae [43].

Given the restrictive inclusion criteria, studies not engaging in clinical trials were excluded. In 2019, Theuretzbacher et al. reviewed the state of research and development of novel antibacterial compounds [44]. The authors stated that most of the candidate molecules are directed against Gram-negative bacteria and some of these novel antibiotics are yet tested in preclinical projects. Further future antibiotic-independent strategies might be host microbiota-altering approaches, vaccines and antibody and bacteriophage therapies, for instance. In support, in a recent case report a patient with a prosthetic infection due to $K$. pneumoniae was subjected to an individualized intravenous phage therapy, which prevented an amputation of the affected limb [45]. Authors from other case reports advocate for the employment of fecal microbial transplantation in patients infected with carbapenem-resistant K. pneumoniae, carbapenem-resistant $K$. oxytoca and enterotoxin-producing Clostridioides difficile strains [46, 47].

Given the presented studies and preclinical approaches, further research is essentially needed. For example, testing the observed beneficial outcomes in larger RCTs, with sufficient study populations, standardized intervention and control groups, is crucial for developing evidence-based treatment options. Exploring novel ideas in alternative therapeutic approaches based on microbiological interactions and immunomodulation might prove helpful for future clinical use.

Regarding the considerations made in the introduction, Bradley et al. showed in a very recent study analysing reported COVID-19 infections that in 19\% of cases bacterial co- and superinfections could be observed, whereas more than $70 \%$ of the patients were subjected to broad-spectrum antibiotic treatment, however, of which $60 \%$ received fluoroquinolones and carbapenems [48]. On the one hand, this elucidates the presence of bacterial superinfections in this viral inflammatory scenario, but also highlights the risk of overtreatment, especially in case of carbapenems.

In conclusion, this literature survey revealed promising treatment options in the combat of infections caused by carbapenem-resistant K. pneumoniae. Further research on novel antibiotic compounds, but also on antibiotic-independent molecules providing synergistic or at least resistance-modifying properties need to be undertaken to have a chance to win the potentially fatal race against emerging antimicrobial resistance in the future.

\section{Ethics statement: Not applicable (literature survey).}

Funding: This work was supported by grants from the German Federal Ministries of Education and Research (BMBF) in frame of the zoonoses research consortium PACCampylobacter (IP7/01KI1725D) and from the Federal Ministry for Economic Affairs and Energy following a resolution of the German National Parliament, Deutscher Bundestag (ZIM, ZF4117908 AJ8) to SB and MMH.

The funders had no role in study design, data collection and analysis, decision to publish or preparation of the manuscript.

Conflict of interest: SB and $\mathrm{MMH}$ are Editorial Board members.

\section{LIST OF ABBREVIATIONS}

$\begin{array}{ll}\text { BAT } & \text { best available therapy } \\ \text { ESBL } & \text { extended spectrum beta-lactamase } \\ \text { ICU } & \text { intensive care unit } \\ \text { KPC } & \text { Klebsiella pneumoniae carbapenemase } \\ \text { MIC } & \text { minimal inhibitory concentration } \\ \text { MDR } & \text { multi-drug resistant } \\ \text { NDM } & \text { New Delhi metallo-beta-lactamase } \\ \text { RCT } & \text { randomized controlled trial } \\ \text { spp. } & \text { species } \\ \text { ssp. } & \text { subspecies } \\ \text { VRE } & \text { vancomycin-resistant enterococci }\end{array}$

\section{REFERENCES}

1. Castanheira M, Deshpande LM, Mendes RE, Canton R, Sader HS, Jones RN. Variations in the occurrence of resistance phenotypes and carbapenemase genes among enterobacteriaceae isolates in 20 years of the SENTRY Antimicrobial Surveillance Program. Open Forum Infect Dis 2019;6(Suppl. 1):S23-33.

2. Årdal C, Balasegaram M, Laxminarayan R, McAdams D, Outterson $\mathrm{K}, \mathrm{Rex} \mathrm{JH}$, et al. Antibiotic development-economic, regulatory and societal challenges. Nat Rev Microbiol 2020;18(5):267-74.

3. Reardon S. Antibiotic treatment for COVID-19 complications could fuel resistant bacteria. Science; 2020. [Internet]. Available from: https:// www.sciencemag.org/news/2020/04/antibiotic-treatment-covid19-complications-could-fuel-resistant-bacteria. Accessed on June 2, 2020.

4. Hsu J. How covid-19 is accelerating the threat of antimicrobial resistance. BMJ 2020;369:1983.

5. Rapp RP, Urban C. Klebsiella pneumoniae carbapenemases in Enterobacteriaceae: history, evolution, and microbiology concerns. Pharmacotherapy 2012;32(5):399-407.

6. Dietel M, Suttorp N, Zeitz M, editors. Harrisons Innere Medizin. 20th ed. Berlin: ABW Wissenschaftsverlag; 2020. 
7. Neu HC. Beta-Lactam antibiotics: structural relationships affecting in vitro activity and pharmacologic properties. Rev Infect Dis 1986; 8(Suppl. 3):S237-59.

8. Noteboom Y, Ong DS, Oostdijk EA, Schultz MJ, de Jonge E, Purmer I, et al. Antibiotic-induced within-host resistance development of gram-negative bacteria in patients receiving selective decontamination or standard care. Crit Care Med 2015;43(12):2582-8.

9. Xia J, Gao J, Tang W. Nosocomial infection and its molecular mechanisms of antibiotic resistance. Biosci Trends 2016;10(1): $14-21$.

10. Hof H, Schlüter D, editors. Medizinische Mikrobiologie.7th ed. Stuttgart: Georg Thieme Verlag; 2019.

11. Gradl G, Teichert M, Kieble M, Werning J, Schulz M. Comparing outpatient oral antibiotic use in Germany and the Netherlands from 2012 to 2016. Pharmacoepidemiol Drug Saf 2018;27(12): 1344-55.

12. Bush K, Bradford PA. $\beta$-lactams and $\beta$-lactamase inhibitors: an overview. Cold Spring Harb Perspect Med 2016;6(8).

13. Birnbaum J, Kahan FM, Kropp H, MacDonald JS. Carbapenems, a new class of beta-lactam antibiotics. Discovery and development of imipenem/cilastatin. Am J Med 1985;78(6a):3-21.

14. Brolund A, Lagerqvist N, Byfors S, Struelens MJ, Monnet DL, Albiger $B$, et al. Worsening epidemiological situation of carbapenemaseproducing Enterobacteriaceae in Europe, assessment by national experts from 37 countries, July 2018. Eurosurveillance 2019;24(9): 1900123.

15. Gandra S, Alvarez-Uria G, Turner P, Joshi J, Limmathurotsakul D, van Doorn HR. Antimicrobial resistance surveillance in low- and middle-income countries: progress and challenges in eight South Asian and Southeast Asian countries. Clin Microbiol Rev 2020;33(3).

16. Lim C, Takahashi E, Hongsuwan M, Wuthiekanun V, Thamlikitkul $\mathrm{V}$, Hinjoy S, et al. Epidemiology and burden of multidrug-resistant bacterial infection in a developing country. Elife 2016;5.

17. Nadimpalli ML, Marks SJ, Montealegre MC, Gilman RH, Pajuelo MJ, Saito M, et al. Urban informal settlements as hotspots of antimicrobial resistance and the need to curb environmental transmission. Nat Microbiol 2020;5(6):787-95.

18. Jajoo M, Manchanda V, Chaurasia S, Jeeva Sankar M, Gautam H, Agarwal R, et al. Alarming rates of antimicrobial resistance and fungal sepsis in outborn neonates in North India. PLoS One 2018; 13(6):e0180705.

19. Chen LF, Anderson DJ, Paterson DL. Overview of the epidemiology and the threat of Klebsiella pneumoniae carbapenemases (KPC) resistance. Infect Drug Resist 5 (2012) 133-41.

20. Podschun R, Ullmann U. Klebsiella spp. as nosocomial pathogens: epidemiology, taxonomy, typing methods, and pathogenicity factors. Clin Microbiol Rev 1998;11(4):589-603.

21. Ko WC, Paterson DL, Sagnimeni AJ, Hansen DS, Von Gottberg A, Mohapatra S, et al. Community-acquired Klebsiella pneumoniae bacteremia: global differences in clinical patterns. Emerg Infect Dis 2002;8(2):160-6.

22. Kidd TJ, Mills G, Sá-Pessoa J, Dumigan A, Frank CG, Insua JL, et al. A Klebsiella pneumoniae antibiotic resistance mechanism that subdues host defences and promotes virulence. EMBO Mol Med 2017;9(4):430-47.

23. Tooke CL, Hinchliffe P, Bragginton EC, Colenso CK, Hirvonen VHA, Takebayashi Y, et al. $\beta$-lactamases and $\beta$-lactamase inhibitors in the 21st century. J Mol Biol 2019;431(18):3472-500.
24. Sanchez GV, Master RN, Clark RB, Fyyaz M, Duvvuri P, Ekta G, et al. Klebsiella pneumoniae antimicrobial drug resistance, United States, 1998-2010. Emerg Infect Dis 2013;19(1):133-6.

25. Chandler JCM, Thomas J, Higgins JPT, Deeks JJ, Clarke MJ. Chapter I: introduction. In: Higgins JPT, Thomas J, Chandler J, Cumpston M, Li T, Page MJ, Welch VA (editors). Cochrane handbook for systematic reviews of interventions. Cochrane; 2019 Version 6. Available from: https://training.cochrane.org/handbook/ current. Accessed on June 5, 2020.

26. Neufassung der Satzung der Charité - Universitätsmedizin Berlin zur Sicherung Guter Wissenschaftlicher Praxis vom 20.06.2012. Zuletzt geänder am 29.03.2018. Amtliches Mitteilungsblatt Charité - Universitätsmedizin Berlin. Nr. 92, S. 658.

27. Ji S, Lv F, Du X, Wei Z, Fu Y, Mu X, et al. Cefepime combined with amoxicillin/clavulanic acid: a new choice for the KPC-producing $K$. pneumoniae infection. Int J Infect Dis 2015;38:108-14.

28. Wunderink RG, Giamarellos-Bourboulis EJ, Rahav G, Mathers AJ, Bassetti M, Vazquez J, et al. Effect and safety of meropenemvaborbactam versus best-available therapy in patients with carbapenem-resistant enterobacteriaceae infections: the TANGO II randomized clinical trial. Infect Dis Ther 2018;7(4): 439-55.

29. Abdelsalam MFA, Abdalla MS, El-Abhar HSE. Prospective, comparative clinical study between high-dose colistin monotherapy and colistin-meropenem combination therapy for treatment of hospital-acquired pneumonia and ventilator-associated pneumonia caused by multidrug-resistant Klebsiella pneumoniae. J Glob Antimicrob Resist 2018;15:127-35.

30. Paul M, Daikos GL, Durante-Mangoni E, Yahav D, Carmeli Y, Benattar YD, et al. Colistin alone versus colistin plus meropenem for treatment of severe infections caused by carbapenem-resistant Gram-negative bacteria: an open-label, randomised controlled trial. Lancet Infect Dis 2018;18(4):391-400.

31. De Pascale G, Martucci G, Montini L, Panarello G, Cutuli SL, Di Carlo D, et al. Double carbapenem as a rescue strategy for the treatment of severe carbapenemase-producing Klebsiella pneumoniae infections: a two-center, matched case-control study. Crit Care 2017;21(1):173.

32. Kaye KS, Bhowmick T, Metallidis S, Bleasdale SC, Sagan OS, Stus $\mathrm{V}$, et al. Effect of Meropenem-vaborbactam vs Piperacillin-tazobactam on clinical cure or improvement and microbial eradication in complicated urinary tract infection: the TANGO I randomized clinical trial. JAMA 2018;319(8):788-99.

33. Lucasti C, Vasile L, Sandesc D, Venskutonis D, McLeroth P, Lala $\mathrm{M}$, et al. Phase 2, dose-ranging study of relebactam with imipenemcilastatin in subjects with complicated intra-abdominal infection. Antimicrob Agents Chemother 2016;60(10):6234-43.

34. Mendes RE, Castanheira M, Woosley LN, Stone GG, Bradford PA, Flamm RK. Molecular $\beta$-lactamase characterization of Gramnegative pathogens recovered from patients enrolled in the ceftazidime-avibactam phase 3 trials (RECAPTURE 1 and 2) for complicated urinary tract infections: efficacies analysed against susceptible and resistant subsets. Int J Antimicrob Agents 2018; 52(2):287-92.

35. Mendes RE, Castanheira M, Woosley LN, Stone GG, Bradford PA, Flamm RK. Characterization of $\beta$-lactamase content of ceftazidimeresistant pathogens recovered during the pathogen-directed phase 3 REPRISE trial for ceftazidime-avibactam: correlation of efficacy 
against $\beta$-lactamase producers. Antimicrob Agents Chemother 2019;63(6).

36. Michalopoulos A, Virtzili S, Rafailidis P, Chalevelakis G, Damala $\mathrm{M}$, Falagas ME. Intravenous fosfomycin for the treatment of nosocomial infections caused by carbapenem-resistant Klebsiella pneumoniae in critically ill patients: a prospective evaluation. Clin Microbiol Infect 2010;16(2):184-6.

37. Motsch J, Murta de Oliveira C, Stus V, Köksal I, Lyulko O, Boucher HW, et al. RESTORE-IMI 1: a multicenter, randomized, doubleblind trial comparing efficacy and safety of imipenem/relebactam vs colistin plus imipenem in patients with imipenem-nonsusceptible bacterial infections. Clin Infect Dis 2019.

38. Hecker SJ, Reddy KR, Totrov M, Hirst GC, Lomovskaya O, Griffith DC, et al. Discovery of a cyclic boronic acid $\beta$-lactamase inhibitor (RPX7009) with utility vs class a serine carbapenemases. J Med Chem 2015;58(9):3682-92.

39. Zhanel GG, Lawrence CK, Adam H, Schweizer F, Zelenitsky S, Zhanel M, et al. Imipenem-relebactam and meropenem-vaborbactam: two novel carbapenem- $\beta$-lactamase inhibitor combinations. Drugs 2018;78(1):65-98.

40. Tumbarello M, Viale P, Viscoli C, Trecarichi EM, Tumietto F, Marchese A, et al. Predictors of mortality in bloodstream infections caused by Klebsiella pneumoniae carbapenemase-producing $K$. pneumoniae: importance of combination therapy. Clin Infect Di 2012;55(7):943-50.

41. Shaeer KM, Zmarlicka MT, Chahine EB, Piccicacco N, Cho JC. Plazomicin: a next-generation aminoglycoside. Pharmacotherapy 2019;39(1):77-93.
42. Connolly LE, Jubb A, O'Keeffe B, Serio AW, Smith A, Gall J, et al. Plazomicin is associated with improved survival and safety compared with colistin in the treatment of serious infections due to carbapenem-resistant enterobacteriaceae: results of the CARE Study. New Orleans: 2nd American Society for Microbiology Microbe; 2017.

43. Wagenlehner FME, Cloutier DJ, Komirenko AS, Cebrik DS, Krause KM, Keepers TR, et al. Once-daily plazomicin for complicated urinary tract infections. N Engl J Med 2019;380(8):729-40.

44. Theuretzbacher U, Outterson K, Engel A, Karlén A. The global preclinical antibacterial pipeline. Nat Rev Microbiol 2020;18(5):275-85.

45. Cano EJ, Caflisch KM, Bollyky PL, Van Belleghem JD, Patel R, Fackler J, et al. Phage therapy for limb-threatening prosthetic knee Klebsiella pneumoniae infection: case report and in vitro characterization of anti-biofilm activity. Clin Infect Dis 2020.

46. García-Fernández S, Morosini MI, Cobo M, Foruny JR, LópezSanromán A, Cobo J, et al. Gut eradication of VIM-1 producing ST9 Klebsiella oxytoca after fecal microbiota transplantation for diarrhea caused by a Clostridium difficile hypervirulent R027 strain. Diagn Microbiol Infect Dis 2016;86(4):470-1.

47. Ponte A, Pinho R, Mota M. Fecal microbiota transplantation: is there a role in the eradication of carbapenem-resistant Klebsiella pneumoniae intestinal carriage? Rev Esp Enferm Dig 2017;109(5): 392.

48. Langford BJ, So M, Raybardhan S, Leung V, Westwood D, MacFadden DR, et al. Bacterial co-infection and secondary infection in patients with COVID-19: a living rapid review and metaanalysis, Clin Microbiol Infect (2020), https://doi.org/10.1016/j.cmi. 2020.07.016. 